"This is the peer reviewed version of the following article: [Georgiadis, A. and Pitelis, C. N. (2016), The Impact of Employees' and Managers' Training on the Performance of Small- and Medium-Sized Enterprises: Evidence from a Randomized Natural Experiment in the UK Service Sector. British Journal of Industrial Relations, 54: 409-421 ]which has been published in final form at [ http:// http://onlinelibrary.wiley.com/doi/10.1111/bjir.12094/abstract ]. This article may be used for noncommercial purposes in accordance with Wiley Terms and Conditions for Self-Archiving." 


\title{
The Impact of Employees' and Managers' Training on the Performance of Small- and Medium-Sized Enterprises: Evidence from a Randomized Natural Experiment in the UK Service Sector
}

\author{
Andreas Georgiadis and Christos N. Pitelis
}

\begin{abstract}
We investigate the relationship between employees' and managers' training and firm performance using a policy intervention that randomly assigned training support to small-and medium-sized enterprises in the UK accommodation and food service sector. Because the number of firms self-selected into training exceeded available places, training was randomly assigned to some firms, resulting in a randomized natural experimental design that allowed us to identify the average effect of training on treated firms. Our empirical results suggest that employees' training had a stronger positive impact on firms' labour productivity and profitability than that of managers'.
\end{abstract}

\section{Introduction}

Economic theory postulates that firms invest in the training of employees in anticipation of a return in the form of higher productivity and profitability (Becker 1962, 1993). In practice, it has been difficult to estimate the return of investment in training to the employer, mainly because of methodological problems related to omitted variables, measurement error and reverse causality (Dearden et al. 2006). Addressing these methodological problems so as to isolate the impact of training on firm performance has been, and remains, a key empirical challenge for studies in the economics and human resource management (HRM) literature (Becker and Huselid 2006; Bloom and Van Reenen 2011; Guest et al. 2003). A fruitful way to progress in this area, suggested by many scholars, is to rely on experimental empirical designs, where training is assigned exogenously (Becker and Huselid 2006; Bloom and Van Reenen 2011).

The few experimental studies purporting to estimate the returns from training to the firm (Bruhn and Zia 2013; Drexler et al. 2014; Karlan and Udry 2012; Karlan and Valdivia 2011; Mano et al. 2012) have mainly focused on the impact of managerial training on the performance of small- and medium-sized enterprises (SMEs) in developing countries (see McKenzie and Woodruff, 2012, for a review).

In the context of developed countries, a few recent studies employed experimental or quasiexperimental variation in training participation of employees in order to estimate the impact of training on individual worker performance (De Grip and Sauermann 2012; Leuven and Oosterbeek 2008). However, there is no experimental evidence from developed countries, to date, on the link between training and firm performance. Moreover, although some authors make a distinction between the training of managers and non-managerial employees and their relative importance for the firm (Lucas 1978; Storey 2004), there has been no empirical study to our knowledge that separately identifies the effect of managers' and non-managerial employees' training on firm performance.

In this article, we address the aforementioned gaps in the literature by leveraging a policy intervention that randomly assigned general training services for managers and for nonmanagerial employees in a sample of SMEs in the UK accommodation and food service sector. Training support was randomly allocated to some of the firms, as a result of the fact that the number of firms self-selected into training exceeded the number of available places. Under this 
randomized natural experimental design, participating firms that did not receive training can provide a valid counterfactual of what would have happened to those firms that received training had they not received it, and allow us to identify the average effect of training on the treated firms.

\section{Conceptual background}

Human capital theory postulates that training (either general or specific) increases the productivity of individual workers, and hence ceteris paribus productivity at the firm, industry and the economy-wide levels (Blundell et al. 1999). Although general training is expected to increase labour productivity at the firm level, the impact of general training on firm profitability will depend on the relative magnitude of training costs and the share of the returns to general training extracted by the firm. That in turn will depend on the degree of firm's labour market power (Acemoglu and Pischke 1998, 1999).

The above predictions do not make a distinction between the impact of general training of managers and non-managers on firm performance, but several studies suggested that these effects are likely to be different (Bruhn et al. 2010, 2012). Managerial human capital, in contrast to that of nonmanagers, may impact firm's output and productivity by improving the marginal productivity of not only managerial inputs but also that of other inputs, such as nonmanagerial labour and physical capital (Bruhn et al. 2010; Penrose 1959). Moreover, improvements in managerial human capital are expected to help relax resource constraints, as managers' decisions are shaping the firm's investment strategy, capital structure and overall business plan (Bennedsen et al. 2007; Bertrand and Schoar 2003). Similarly, the impact of managers' training on firm profitability may be different from that of non-managerial employees. For example, Manning (2003) suggested that there are reasons to believe that the labour market for more skilled workers is less monopsonistic than that for the less-skilled, as a result of the higher profit opportunities for firms, which increase competition between firms and drive up skilled labour wages.

\section{The public policy intervention and the selection of businesses}

\section{The Public Policy Intervention}

In the UK, the government has placed knowledge and skills at the centre of its strategy to improve the growth capability of UK SMEs and foster national competitiveness and productivity (Small Business Service 2002). As a response to that objective, a number of training initiatives for SMEs have been introduced in the UK over the last decade (OECD 2002; Storey 2004).

One of these initiatives was launched in 2001 by the Department for Business Innovation and Skills (BIS) (formerly known as the Department for Trade and Industry (DTI)), with the objective to foster growth, productivity and performance of SMEs in the accommodation and food service sector (DTI 2004) through the provision of 'support services'. The initiative that was funded by the BIS was also supported by all trade associations in the sector and was initially expected to support more than 1,000 businesses participating in the business support programmes.

Support programmes targeted key areas of SMEs' weaknesses, such as employees' general skills, innovation, marketing, as well as product and service quality (DTI 2004). In particular, the first wave of support programmes provided by the BIS were solely engaged in advancing employees' and managers' general skills and the general human capital of participating 
businesses by providing training services. This is because the lack of skilled workforce was identified as the most important limitation faced by SMEs (Small Business Service 2001, 2002).

The first wave of BIS support programmes was implemented between September 2002 and August 2003, and involved three formal ${ }^{1}$ training services aiming to upgrade the general human capital of participating SMEs. These services included a training programme for nonmanagerial employees and two training programmes for managers. The training programme for employees (we label this as the 'employees' training' service) aimed to develop the general skills of non-managerial staff and to increase their productivity. The training programmes for managers included two programmes. One programme targeted general managerial skills (we label this the 'managers' training' service) aiming at helping business owners/managers (Forth et al. 2006) to develop skills and expertise related to the running of the business and decision making. The second programme aimed at improving the general HRM skills of managers (we label this the 'HRM training' service) by promoting best practice in selection, recruitment and retention of employees.

Each of the general training services was delivered by certified business consultants onsite and free of charge to the selected businesses, while the duration, intensity and content of each service were the same for all businesses. In particular, the 'employees' training' service included two modules delivered to all non-managerial employees of the business. The first module focused on the delivery of effective and reliable customer service, and the second module on improving business literacy, numeracy and communications skills. Each module included four two-hour sessions, and the two modules were delivered interchangeably on a weekly basis (more details on the content of the 'employees' training' and the other two training services are available from the authors on request). Training under this service began in September 2002 and lasted nine weeks to account for one final review session.

Similarly, the 'managers' training' service was provided to all managerial employees of the business and was organized in three modules: module one was on assertiveness and delegation and comprised two two-hour sessions; module two and three were on financial management and on developing a business plan, respectively, and included four two-hour sessions each. The total training time under this service was 10 weeks, with the three modules being delivered sequentially on a weekly basis starting with module one and followed by modules two and three. The 'managers training service' began in January 2003, so as not to run in parallel to the 'employees' training' service, as this would place more demands in terms of employees' and managers' time over a shorter time span for those businesses selected to receive both services. Finally, the 'HRM training' service, which began in June 2003 and lasted for eight weeks, was provided to all managerial employees and included four focused two-hour workshops delivered biweekly. The objective of this service was to provide a review of business performance in the areas of selection, recruitment and retention of workforce, to present case studies of best practices, and to offer tips for improvements.

\section{The Selection of Businesses}

The procedure for business selection in the BIS business support programme and the allocation of training services were as follows: in the first stage, businesses were contacted using information from the yellow pages business database, employing a stratified randomized procedure. In particular, trade associations in the sector contacted randomly a number of businesses from each UK region, with the number of contacted businesses in each region being proportional to the region's share in the population of SMEs in the sector. All contacted 
businesses that expressed willingness to participate in the programme and had less than 250 employees (hence satisfied the European Commission definition of an SME (European Commission 2002)) were enlisted in the programme that involved the provision of all three training services (no record was kept of the contacted firms that were not interested in participating in the programme). The process of contacting businesses was completed after a target number of eligible firms willing to participate in the programme were reached (for the first wave, this target was circa 1,350 firms). The target number of firms was based on a rough estimate of the availability of funds provided by the BIS in eachUKregion. The precise amount of funds allocated to training provision in each region was determined by the BIS after the first stage of business selection.

In the second stage of the programme, the allocation of each training service across programme-participating businesses was determined by funding availability in the region, with less competitive regions and regions with more programme-enlisted firms being allocated more funds. In the case regional funding was not sufficient to provide the training service to all enlisted businesses in the region, the service was allocated by a random lottery. As the number of businesses eligible to receive each training service exceeded the number of businesses that can be supported by the service in all regions, all three training services were randomly assigned within each region. As a result, some businesses received all three services, whereas others received a combination of two, one or none of the services. In particular, 480 businesses received no service, 178 businesses received all three services, while 168, 56 and 20 businesses received only the 'employees' training', the 'managers' training' and the 'HRM training' service, respectively. Moreover, 117 businesses received both the 'employees' training' and the 'managers' training' service, 14 businesses received the 'employees' training' and the 'HRM training' service, and 22 businesses received both the 'managers' training' and the 'HRM training' service.

The random assignment of the training services across businesses forms the key feature of our empirical strategy employed to evaluate the impact of the training intervention on the performance of participating businesses. Compliance with the provision of each service was full, as all firms selected to receive each service took the service and completed the training, and no service was provided to any firm not initially selected to receive a service. Generally, such a complete take-up and completion of training by all selected businesses is quite rare (Bruhn et al. 2012; Karlan and Valdivia 2011), an exception being Mano et al. (2012). In our case, we believe that this can be attributed to the several characteristics of the service provision, such as the involvement of the trade associations and that care was taken to minimize the (real and opportunity) costs to the employees and the business as a whole. In particular, the services were delivered (a) free of charge, (b) in-house, and (c) outside business operation times and at times that were convenient for employees and managers.

\section{The data}

The analysis of the impact of each training service on the performance of participating businesses is based on two datasets: one includes information on a few key characteristics of participating businesses just before the implementation of training services in 2002, extracted from the database of the British hospitality association. The other was from data collected as part of a follow-up survey implemented after the completion of training provision. The followup survey was implemented around two years after the completion of BIS training provision to the selected firms, between November 2005 and February 2006, by the authors of this article, in close collaboration with trade associations of the accommodation and food service sector. 
The survey included multiple contacts of all programme-participating businesses. The first step was to notify businesses about the survey, and the second involved mailing the questionnaire and several follow-ups aiming to enhance the response rate (Dillman 1999). The questionnaire was informed by theory and from focus group discussions with chief executive officers of the trade associations and business owners/managers (the questionnaire is available from the authors on request) and included questions on key financial and other performance indicators, such as sales revenue, total expenditure and advertising expenditures of the last completed financial year, and on factors determining business performance. The questionnaire was kept short (four pages) and simple, partly because of concerns of a low-response rate and partly because focus groups discussions revealed that in contrast to large firms, the organizational structure of SMEs in the UK accommodation and food service sector is quite simple.

The survey achieved a rather high response rate (32 per cent), as compared with the average response rate for SMEs in this sector (that is less than 20 per cent according to Dillman 1999), with 430 businesses returning the survey questionnaire. The information collected was of high quality, as the vast majority of managers provided detailed answers to all questions.

Table 1 presents summary statistics of baseline characteristics, obtained from the database of the British hospitality association, for businesses that responded in the follow-up survey and of key business outcomes observed in the follow-up survey. Baseline information on sales revenue and number of employees was reported in bands, but sales revenue was missing for more than 50 per cent of the businesses, and this is why it is not reported here.

Baseline characteristics suggest that the majority of businesses were small (less than 100 employees), were hotels, restaurants or pubs, and mostly limited companies located in a rural area. The follow-up survey statistics suggest that two years after the baseline information was collected, the same businesses had on average around two million pounds annual sales revenue, an annual profit margin of 22 per cent and 54 employees.

TABLE 1

Descriptive Statistics for Baseline Characteristics and Post-Intervention Business Outcomes for Businesses That Responded in the Follow-Up Survey

\begin{tabular}{|l|l|l|l|}
\hline \multicolumn{2}{|l|}{ Baseline characteristics } & \multicolumn{2}{l|}{ Business outcomes in the follow-up survey } \\
\hline $\begin{array}{l}\text { Less than } 100 \\
\text { employees }\end{array}$ & $0.85(0.35)$ & Sales revenue (£000) & $2,172.86(4,091.75)$ \\
\hline $\begin{array}{l}\text { Hotels, restaurants, } \\
\text { bar and pubs }\end{array}$ & $0.53(0.50)$ & Number of employees & $54(105.13)$ \\
\hline Limited company & $0.51(0.50)$ & $\begin{array}{l}\text { Sales revenue per } \\
\text { employee } \\
(£ 000)\end{array}$ & $88.15(232.89)$ \\
\hline Urban & $0.37(0.48)$ & Profit margin & $0.22(0.96)$ \\
\hline $\begin{array}{l}\text { Number of } \\
\text { observations }\end{array}$ & 430 & & 430 \\
\hline
\end{tabular}

Notes: Statistics reported include shares of firms with a given characteristic for baseline characteristics and averages for business outcomes in the follow-up survey. Standard deviations in parentheses. Except for hotels, restaurants, bars and pubs, $47 \%$ of businesses in our sample include attractions, contract catering, caravan/home sales and other serviced accommodation. Except of limited companies, $49 \%$ of businesses in our sample are partnerships and sole proprietorships. 


\section{Results}

The key feature of the empirical strategy we employ to estimate the impact of training services on business performance is the random assignment of training services across firms. In practice, random assignment of training services among survey respondents might have failed, either because it has not been initially successfully implemented among all participants (these included 1,325 businesses, 430 responding and 895 not responding to the follow-up survey), or if there is sample selection arising from non-response that is correlated with the provision of training, or both.

In order to test whether training services were randomly assigned, we estimated linear probability models, separately for each baseline characteristic, of whether a business was assigned or not a given training service, including as explanatory variables region dummies and dummies for the baseline characteristic ${ }^{2}$ (these estimation results are available from the authors on request). We found no systematic difference between treatment and control groups in terms of baseline characteristics within a given region. In some cases, we found weakly significant differences between treatment and control groups in the distribution of baseline characteristics that can arise from chance factors. However, controlling for these characteristics in the estimation can deal with any bias in the estimated impact of the intervention on business outcomes arising from chance differences at baseline (Duflo et al. 2007). ${ }^{3}$

The impact of each training service on business performance outcomes was estimated using the following specification:

$y_{i t}=\beta_{0}+\beta_{1} T i, E S, t-1+\beta_{2} T i, M S, t-1+\beta_{3} T i_{, H R M S}, t-1+\beta_{4}{ }^{\prime} X i_{, t-1}+u_{i t}$

where $y_{i t}$ is an outcome for business $i$ observed at time $t$, that is the timing of the follow-up survey; Ti,ES, $t-1, T i, M S, t-1$ and Ti,HRMS,t-1 are dummies that take the value one if business $i$ received the 'employees' training', the 'managers' training' and the 'HRM training' service, respectively, at baseline, and are zero otherwise; $X i, t-1$ is a vector including all business characteristics observed at baseline; and $\beta 1, \beta 2, \beta 3$ are coefficients, whereas $\beta 4$ is a vector of coefficients.

Under random assignment of training support, training dummies are expected to be uncorrelated with the error term in equation (1), and ordinary least squares (OLS) is expected to yield unbiased estimates of the impact of each training service on business outcomes. Moreover, under the maintained assumptions, OLS identifies the average treatment effect on the treated (ATT), that is the average effect on the subpopulation of businesses that are selfselected into treatment (treatment here refers to programme participation and not training provision). Under heterogeneous treatment effects, the ATT is different from the average treatment effect (ATE), that is the average impact of the treatment on businesses of a certain type as if they were randomly assigned to it (Blundell and Costa Dias 2009). Thus, in our case, OLS identifies the impact of training services on businesses in the sector that would be willing to take up fully subsidized training. Provided that these businesses have the highest actual gains from training, this impact is expected to be higher than the impact of training on the average SME in the sector.

Moreover, from a policy point of view, the effect of interest is the ATT, as the assignment of businesses into treatment under the ATT more closely resembles the actual policy take-up. 
Table 2 presents estimation results from two specifications for log sales revenue per employee and profit margin (profit as a share of sales revenue), two well-established measures of labour productivity and profitability in the literature (Huselid 1995).

Estimation results suggest that the 'employees' training' has a sizeable positive and statistically significant impact on both log sales revenue and profit margin. In particular, our estimates suggest that two years after the completion of the 'employees' training' service, businesses that received the service had on average 87 per cent higher sales revenue per employee and 18 per cent higher profit margin than businesses that did not receive the service. ${ }^{4}$ Moreover, we find that businesses that received the 'managers' training' service had, on average, 24 per cent higher profit margin two years after the completion of the service, as compared with businesses that did not receive the service, but these differences are weakly significant. Estimates in Table 2 also suggest that neither the 'managers' training' service nor the 'HRM training' service had a significant impact on business profitability, and that the latter service had also no impact on labour productivity. We also find that compared with businesses that did not receive any service, businesses that received at least one of the training services had on average 72 and 22 per cent higher sales revenue per employee and profit margin, respectively (with differences in profit margins being weakly significant).

We also estimated specifications, including interactions of the training services, to test for complementarities between training services, but we found no significant effects. The lack of significance of the coefficients of the interaction terms may not necessarily imply that there are no complementarities, as it may be due to low statistical power, given the size of the sample.

TABLE 2

OLS Estimates of the Impact of Training Services on Business Outcomes

\begin{tabular}{|l|c|c|c|c|}
\hline \multirow{2}{*}{} & \multicolumn{2}{|c|}{$\begin{array}{c}\text { Log sales revenue per } \\
\text { employee }\end{array}$} & \multicolumn{2}{c|}{ Profit margin } \\
\cline { 2 - 5 } & $(1)$ & $(2)$ & $(1)$ & $(2)$ \\
\hline Employees' training service & $\begin{array}{c}0.630^{* * *} \\
(0.105)\end{array}$ & - & $\begin{array}{c}0.177^{* *} \\
(0.074)\end{array}$ & - \\
& $\begin{array}{c}0.221^{*} \\
(0.119)\end{array}$ & - & 0.095 & - \\
\hline Managers' training service & 0.149 & - & $0.106)$ & \\
& $(0.130)$ & & $(0.067)$ & - \\
\hline HRM training service & - & $0.544^{* * *}$ & - & $0.242^{*}$ \\
\hline At least one training service & & $(0.107)$ & & $(0.132)$ \\
\hline R-squared & 0.190 & 0.135 & 0.067 & 0.065 \\
\hline Number of observations & 430 & 430 & 430 & 430 \\
\hline
\end{tabular}

Notes: Standard errors in parentheses. All specifications include controls for region, number of employees, industry, ownership type and location at baseline.

$* p$-value $<0.10 ; * * p$-value $<0.05 ; * * * p$-value $<0.01$.

OLS, ordinary least squares; HRM, human resource management.

\section{Discussion and conclusions}

One of the most important gaps in the HRM and economics literature is the lack of robust evidence on the causal impact of training on firm performance. The few existing experimental studies that address this gap provide evidence of the impact of managers' training on the performance of SMEs in developing countries. Moreover, there are no experimental studies of 
that kind in developed countries, and no study to date that has purported to identify separately the impact of managers' and non-managerial employees' training on firm performance.

In this article, we address these gaps in the literature by investigating the impact of a policy intervention that randomly assigned free general training services for managers and for nonmanagerial employees on the performance of SMEs in the UK accommodation and food service sector. The randomized natural experimental design allowed us to identify the average effect of training on treated firms.

We found that non-managerial employees' training had a large positive impact on labour productivity and profitability, whereas there was a weak or no effect of managerial and HRM training services on firm performance. Our results for employee training may reflect a tendency for managers in treated firms to over-report performance in order to justify the receipt of free training (Bruhn et al. 2012), although our results of a weak or no effect of managerial and HRM training on firm performance lead us to think that this is unlikely.

By construction, our estimate of the ATT reflects the overall or net effect of the training intervention on firm performance that combines the effects operating through all possible adjustments or channels. Although the net effect of training on performance is positive, it is possible that some of these adjustments lead to a reduction in performance. For example, additional exploratory analysis revealed that both employee and manager training had a negative effect on a measure of expenditures on external business support (including training), which suggests that the former partly substitutes for the latter

It is also possible that firms that volunteer for a free training programme are also the most constrained in their ability to invest in employee training and those likely to benefit the most by these services. Although we are unable to address this possibility, this would mean that our estimates of the impact of employee training exaggerate the impact of training on the average SME in the sector, and thus can explain the large effect of employee training on performance in our study.

Finally, we cannot be certain as to why employee training seems to have stronger implications for performance than managerial or HRM training. But this finding is consistent with the argument that employee skill are greater than managerial skill shortages, and hence the contribution of employee training to performance may be greater than that of managerial and HRM training. This argument could thus account for the larger effect of employees' training compared with managers' training on labour productivity. Businesses in this sector may also have more labour market (monopsony) power over employees than over managers (Manning 2003), and thus are able to capture higher profits from employee training. This could explain the larger impact of employee training compared with manager training on firm profitability.

Overall, the large impact of training on performance of these businesses is consistent with earlier studies that find substantial returns to the firm from the training of employees (Bartel 2000; Blundell et al. 1999; Bruhn et al. 2012).

Our study provides rare evidence that could inform the current hot debate on the potential importance of public industrial policies and the types of public policies that are more likely to bear positive economic outcomes (Warwick 2013). In particular, it provides support for training support policies to SMEs that are targeted in terms of the sector and firm size, but otherwise horizontal to all targeted firms. 


\section{Acknowledgement}

We would like to thank the editor and two anonymous referees for valuable feedback. Errors are ours.

\section{Notes}

1. According to the OECD, formal training has the following characteristics: (a) employees are taught skills or given information to help them do their job better, (b) it is planned in advance, and (c) it has a structured format and a defined curriculum (OECD 2002).

2. If $D, Y$ and $R$ are binary variables, with $D$ taking the value 1 if the business has received a given training service and 0 otherwise, $Y$ taking the value 1 if the business has a given characteristic and 0 otherwise, and $R$ taking the value 1 if the business is located in a given region and 0 otherwise, then randomization, conditional on region implies that one can show that implies In particular, using the fact that, that, and that, can be written as follows: that further implies, that is based on the above assumptions, (Angrist and Pischke 2009), with and coefficients. Under the assumption that, conditional on region, the probability that a given training service is assigned to a firm of a given characteristic does not vary with region, can be written as follows: implies that testing is equivalent to testing. The latter condition can be tested by running a regression of $D$ on $Y$ and $R$ and testing whether the estimated coefficient of $Y$ is significantly different than zero.

3. We have also failed to find evidence of systematic differences at baseline between businesses receiving and not receiving each training service in the sample of all 1,325 businesses and evidence that survey non-response was correlated with training provision. Results are available on request.

4. Because the dependent variable is in logs and the 'treatment' variable is binary, the difference in the outcome between businesses that received and those that did not received the service in percentage terms is equal to $(e \beta-1) * 100$, where $\beta$ is the coefficient of the 'treatment' variable.

\section{References}

Acemoglu, D. and Pischke, J. S. (1998). 'Why do firms train? Theory and evidence'. Quarterly Journal of Economics, 113: 78-118.

and - (1999). 'Beyond Becker: training in imperfect labour markets'. Economic Journal, 109: 112-42.

Angrist, J. and Pischke, J. S. (2009). Mostly Harmless Econometrics: An Empiricist's Companion. Princeton, NJ: Princeton University Press.

Bartel, A. (2000). 'Measuring the employer's return on investment in training: evidence from the literature'. Industrial Relations, 39: 502-24. 
Becker, B. E. and Huselid, M. A. (2006). 'Strategic human resources management: where do we go from here?' Journal of Management, 32: 898-925.

Becker, G. (1962). 'Investment in human capital: a theoretical analysis'. Journal of Political Economy, 70: 9-49.

(1993). Human Capital: A Theoretical and Empirical Analysis, With Special Reference to Education, 3rd edn. Chicago, IL: University of Chicago Press.

Bennedsen, M., Nielsen, K. M., Perez-Gonzalez, F. and Wolfenzon, D. (2007). 'Inside the family firm: the role of families in succession decisions and performance'. Quarterly Journal of Economics, 122: 647-91.

Bertrand, M. and Schoar, A. (2003). 'Managing with style: the effect of managers on firm policies'. Quarterly Journal of Economics, 118: 1169-208.

Bloom, N. and Van Reenen, J. (2011). 'Human resource management and productivity'. In O. Ashenfelter and D. Card (eds.), Handbook of Labor Economics, Vol. 4b. Amsterdam: NorthHolland, pp. 1607-767.

Blundell, R. and Costa Dias, M. (2009). 'Alternative approaches to evaluation in empirical microeconomics'. Journal of Human Resources, 44: 565-640.

— Dearden, L., Meghir, C. and Sianesi, B. (1999). 'Human capital investment: the returns from education and training to the individual, the firm and the economy'. Fiscal Studies, 20: $1-23$.

Bruhn, M., Karlan, D. A. and Schoar, A. (2010). 'What capital is missing in developing countries?' American Economic Review: Papers \& Proceedings, 100: 629-33.

— - and (2012). 'The Impact of Consulting Services on Small and Medium Enterprises: Evidence from a Randomized Trial in Mexico'. Economics Department Working Paper No. 100, Yale University.

and Zia, B. (2013). 'Stimulating managerial capital in emerging markets: the impact of business training for young entrepreneurs'. Journal of Development Effectiveness, 5: 232-66.

Dearden, L., Reed, H. and Van Reenen, J. (2006). 'The impact of training on wages and productivity: evidence from British panel data'. Oxford Bulletin of Economics and Statistics, 68: 397-421.

De Grip, A. and Sauermann, J. (2012). 'The effects of training on own and co-worker productivity: evidence from a field experiment'. Economic Journal, 122: 376-99.

Department of Trade and Industry (DTI) (2004). 'Raising UK Productivity — Developing the Evidence Base for Policy'. Economic Paper No. 8, Department of Trade and Industry, London.

Dillman, D. (1999). Mail and Internet Surveys: The Tailored Design Method. New York: Wiley. 
Drexler, A., Fisher, G. and Schoar, A. (2014). 'Keeping it simple: Financial literacy and rules of thumbs'. American Economic Journal: Applied Economics, 6: 1-31.

Duflo, E., Glennerster, R. and Kremer, M. (2007). 'Using randomization in development economics research: a toolkit'. In T. P. Schultz and J. Strauss (eds.), Handbook of Development Economics, Vol. 4. Amsterdam: North-Holland, pp. 3895-962.

European Commission (2002). Small and Medium Sized Enterprises in Focus. Brussels: Observatory of European Small and Medium Sized Enterprises.

Forth, J., Bewley, H. and Bryson, A. (2006). 'Small and Medium-Sized Enterprises: Findings from the 2004 Workplace Employment Relations Survey'. Department for Trade and Industry Report.

Guest, D. E., Michie, J., Conway, N. and Sheenan, M. (2003). 'Human resource management and corporate performance in the UK'. British Journal of Industrial Relations, 41: 291-314.

Huselid, M. A. (1995). 'The impact of human resource management practices on turnover, productivity, and corporate financial performance'. Academy of Management Journal, 38: 635-72.

Karlan, D. A. and Udry, C. (2012). 'Management Capital and Firm Organization in among Small-Scale Enterprises in Ghana'. Yale mimeo.

-and Valdivia, M. (2011). 'Teaching entrepreneurship: impact of business training on microfinance clients and institutions'. Review of Economics and Statistics, 93: 510-27.

Leuven, E. and Oosterbeek, H. (2008). 'An alternative approach to estimate the wage returns to private-sector training'. Journal of Applied Econometrics, 23: 423-34.

Lucas, R. (1978). 'On the size of distribution of business firms'. Bell Journal of Economics, 9: 508-23.

McKenzie, D. and Woodruff, C. (2012). 'What Are We Learning from Business Training and Entrepreneurship Evaluations Around the Developing World?' The World Bank, Policy Research Working Paper No. 6202.

Manning, A. (2003). Monopsony in Motion: Imperfect Competition in Labor Markets.

Princeton, NJ: Princeton University Press.

Mano, Y., Iddrisu, A., Yoshino, Y. and Sonobe, T. (2012). 'How can micro and small enterprises in sub-Saharan Africa become more productive? The impacts of experimental basic managerial training'. World Development, 40: 458-68.

OECD (2002). Management Training in SMEs. OECD Report. Paris: OECD.

Penrose, E. T. (1959). The Theory of the Growth of the Firm, 3rd edn. Oxford: Oxford University Press. 
Small Business Service (2001). Small Firms, Big Business: A Review of Small and Medium Sized Enterprises in the UK. London: HMSO.

_ (2002). Small Business and Government - The Way Forward. London: HMSO.

Storey, D. (2004). 'Exploring the link among small firms between management training and firm performance: a comparison between the UK and other OECD countries'. International Journal of Human Resource Management, 15: 112-30.

Warwick, L. (2013). 'Beyond Industrial Policy: Emerging Issues and New Trends'. OECD Science, Technology and Industry Policy Papers, No. 2. 